There are useful chapters on the clinical use of antilymphocyte globulin (Barnes), the specific correction of immune defects (Buckley), the immunotherapy of leukaemia (Freeman) and the treatment of allergic disease (Smith) for those clinical immunologists who practise their art with a stethoscope in one hand and a syringe of gammaglobulin in the other. One can add a sour note by pointing out that in at least one of the topics, "recent advances" appear to have followed a circular course. The measurement of immune complexes (Zubler and Lambert), the enumeration of $T$ and $B$ lymphocytes (Hayward and Greaves), and the assessment of granulocyte function (Bjorkstein and Quie) are dealt with in chapters written by experienced and knowledgeable authors; these chapters will prompt the clinical pathologists to review the services they provide, particularly in specialised centres. Finally, intellectually curious doctors, irrespective of their official commitments, will enjoy reading the remaining chapters in their armchairs.

The immunological problems of protein malnutrition (Douglas and Faulk), ageing (Adler, Jones and Nariuchi) and amyloidosis (Rosenthal and Franklin) are dealt with in highly competent academic essays. However, much of the material is esoteric or derived from animal experiments.

Some additional comments are unavoidable. In the face of the current plethora of new immunological texts, it would take miracles of innovative imagination for successive publications to provide much that is fresh or novel. This book contains nothing that has not been summarised elsewhere, often several times over. Nor does it provide a comprehensive guide to any facet of clinical immunology. In a discursive anthology, it would also be reasonable to anticipate a modicum of prophetic utterance or even quixotry. Unfortunately, despite its brave title, the first volume in the series disabuses the reader of any such expectations.

A. M. Denman

\title{
Antifungal compounds
}

Edited by M. R. Siegel and H. D. Sisler. 1977. Vol. 2; Interactions in biological and ecological systems. New York and Basle: Marcel Dekker Inc. Pp. xiv and 674. SwF 205.

The medical microbiologist will find little of interest in this volume which is almost entirely concerned with fungicides in agriculture and horticulture. Of the antifungal drugs considered in Volume I, the most important currently used for the treatment of systemic fungal infections, amphotericin B, 5-fluorocytosine, clotrimazole and miconazole, are not even mentioned here.

In a chapter entitled " Effect of fungicides on nucleic acid synthesis and nuclear function ", Dekker states that after oral administration of griseofulvin, the growth of the fungi in the skin cells is inhibited and the actual killing of the fungus is not necessary, as the keratinised cells are thrown off. In temperate climates, most dermatologists use topical remedies for smooth skin infections and reserve griseofulvin for infections of the scalp and chronic infections involving the nails. The fact that griseofulvin is fungistatic is probably the reason why toe nail infections, even if they improve, all too frequently relapse when griseofulvin therapy is stopped.

The physician concerned with industrial hazards in agriculture and horticulture will find this volume a useful source of information on the toxicity, activity, biological conversion and degradation of fungicides in common use. For that reason, it should be available in the appropriate reference libraries.

\section{R. R. DAVIES}

\section{Man meets microbes}

By Jennifer R. Jamison. 1977. Sevenoaks, Kent: The Butterworth Group. Pp. xiii and 216. $£ 7 \cdot 15$.

This is, on the whole, a well written, up-to-date account of medical microbiology, intended for students of nursing and allied medical disciplines. It contains perhaps rather more than required for the average nurse in the UK, but will be a fine book for a nurse with an enquiring 